\title{
A expansão do agronegócio no semiárido cearense e suas implicações para a saúde, 0 trabalho e 0 ambiente
}

Marcelo José Monteiro Ferreira(a)

Mário Martins Viana Júnior ${ }^{(b)}$

Ferreira MJM, Viana Júnior MM. The expansion of agribusiness in Ceará semiarid region and their implications for health, work and environment. Interface (Botucatu). 2016;

20(58):649-60.

Since 2008, Brazil is the worldwide leader in pesticide's consumption. On the other hand, looking through a public health lens, the rates of intoxication by pesticides are rising - they reached 9.000 notifications in the year of 2012 only. The present paper aims to analyze the transformations occurred in lifestyles and its implications in health, work and environment due the insertion/expansion of agribusiness in Ceará's semiarid. For that, we adopted research-action as methodology. As method, we used the Social Cartography and non-structured interview as technique. The analysis of the qualitative material was made by discourse analysis. Through participation in workshops it could be experienced a development of a collective consciousness in the participants of this research. Through the criticism of their own reality, they were able to question and achieve a deeper knowledge about transformations that affect their own territories, as a consequence of agribusiness.

Keywords: Social vulnerability. Environmental exposure. Pesticides. Rural settlements. Consumer participation.
Desde 2008, o Brasil é o líder mundial em consumo de agrotóxicos. Em contrapartida, do ponto de vista da saúde pública, aumentam as taxas de intoxicação por agrotóxicos que, somente em 2012, superaram as nove mil notificações. $\mathrm{O}$ presente artigo tem como objetivo uma análise das transformações ocorridas nos modos de vida - e suas implicações para a saúde, o trabalho e o ambiente decorrentes da introdução/expansão do agronegócio no semiárido cearense. Para tanto, adotamos como metodologia a Pesquisa-ação. Como método, utilizamos a Cartografia Social e a entrevista não estruturada como técnica. A análise do material qualitativo deu-se por meio da Análise de Discurso. Por intermédio das oficinas, pudemos experimentar, na prática, o desenvolvimento da consciência coletiva dos sujeitos participantes da pesquisa. Ao problematizarem sua própria realidade, obtiveram maior profundidade sobre as transformações que incidem em seus territórios, decorrentes do agronegócio.

Palavras-chave: Vulnerabilidade social. Exposição ambiental. Agrotóxicos. Assentamentos rurais. Participação comunitária.

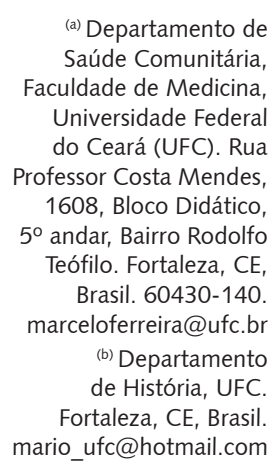

(a) Departamento de Saúde Comunitária, Faculdade de Medicina, Universidade Federal do Ceará (UFC). Rua Professor Costa Mendes, 1608, Bloco Didático, $5^{\circ}$ andar, Bairro Rodolfo Teófilo. Fortaleza, CE, Brasil. 60430-140. marceloferreira@ufc.br (b) Departamento de História, UFC. Fortaleza, CE, Brasil. mario_ufc@hotmail.com 


\section{Introdução}

Desde 2008, o Brasil lidera o ranking mundial como o país que mais importa agrotóxicos no mundo, sendo responsável por $86 \%$ do total consumido na América Latina 1 . Somente no ano de 2010, a taxa de crescimento das vendas no país foi de $190 \%$, enquanto, no resto do mundo, foi de $93 \%^{2}$, ocupando, assim, um lugar de destaque no cenário internacional como o mais importante nicho para o crescimento econômico das empresas transnacionais produtoras desses insumos químicos.

Durante o ano de 2011, o mercado nacional movimentou cerca de US\$ 8,5 bilhões de dólares. As lavouras de soja, milho, algodão e cana-de-açúcar foram responsáveis por $80 \%$ das vendas do setor ${ }^{3}$. Dentre os princípios ativos mais utilizados nas culturas, os herbicidas assumem o primeiro lugar. Suas vendas passaram de US\$1.360.895, em 2010, para US\$1.860.919 em 20124. Registra-se, também, o aumento do consumo médio de ingredientes ativos em relação às áreas cultivadas, saltando de 7,56 t/ha, em 2005, para 18,36 t/ha em 20123.

Todavia, os números assinalados acima invisibilizam as consequências dos efeitos deletérios dos agrotóxicos para a saúde humana e o equilíbrio ecológico. Do ponto de vista da saúde pública, identificamos um incremento das taxas de intoxicações por agrotóxicos registradas pelo Sistema de Informação de Agravos de Notificação (SINAN), que, somente em 2012, notificou mais de nove mil $\operatorname{casos}^{5}$. Ressaltamos que, de acordo com a Organização Mundial da Saúde (OMS), para cada caso confirmado, estima-se a presença de outros cinquenta subnotificados, o que nos levaria a um quantitativo de, aproximadamente, quatrocentos e cinquenta mil casos, representando, assim, um grave problema de saúde pública. Somam-se, ainda, os acidentes de trabalho decorrentes de intoxicações por agrotóxicos que, em 2011, foram $126,77 \%$ a mais que em $2007^{6}$. Outro aspecto preocupante diz respeito à faixa etária das intoxicações, atingindo, sobretudo, os indivíduos do sexo masculino de 20 a 34 anos $^{7}$.

Esse contexto de exposição a agrotóxicos reproduz-se, também, no semiárido cearense, mais precisamente no baixo Jaguaribe, distante cerca de duzentos quilômetros da capital Fortaleza, no Ceará. Desde a década de 1980, a região registra a chegada de grandes empresas transnacionais e regionais do agronegócio, que vêm modificando sobremaneira os modos de vida e o perfil de morbimortalidade daquela população ${ }^{8}$.

Nesse contexto, estudo epidemiológico realizado em três municípios situados no baixo Jaguaribe (Limoeiro do Norte, Russas e Quixeré) evidenciou um incremento anual das taxas de internação por neoplasias 1,76 vezes maiores quando comparadas as de outros 11 municípios controle. Ademais, as análises registraram que a taxa de mortalidade por câncer é 38\% maior nos três municípios supracitados, demonstrando a influência dos processos produtivos sobre o perfil de adoecimento e morte das populações ${ }^{9}$.

No que tange à preocupação com os agravos à saúde, pesquisa realizada durante o período de 2007 a 2011, evidenciou, dentre outros, que 97\% dos trabalhadores do agronegócio e dos agricultores familiares estudados estavam expostos a agrotóxicos. Tal exposição envolvia a presença de quatro a trinta ingredientes ativos distintos, distribuídos entre inseticidas, herbicidas e fungicidas. No conjunto dos dados, foi possível identificar a presença de 25 grupos químicos diferentes, dos quais $68,5 \%$ são classificados como extremamente tóxicos ou muito tóxicos ${ }^{8}$.

Do ponto de vista da exposição ambiental, merece destaque a prática da pulverização aérea com fungicidas de classes toxicológicas I e II (extremamente e altamente tóxicos, respectivamente) nos cultivos de banana, extensamente produzidos na região9. Tais práticas contribuem sobremaneira para a contaminação ambiental, em especial dos lençóis freáticos. Acerca disso, estudos realizados pelo órgão estadual de recursos hídricos do Ceará detectaram a presença de Ingredientes Ativos (IA) em seis de dez amostras provenientes do aquífero Jandaíra, colocando em risco a segurança hídrica da população ${ }^{10}$. Além disso, é importante salientarmos que, em 2014, o estado do Ceará decretou estado de emergência em $92 \%$ dos seus municípios em virtude da severa e prolongada estiagem ${ }^{11}$.

Desse modo, a conjuntura dos fatores elencados foi motivadora para adotarmos, como objetivo do presente manuscrito, uma análise das transformações ocorridas nos modos de vida - e suas implicações 
para a saúde, o trabalho e o ambiente - decorrentes da introdução/expansão do agronegócio na região do baixo Jaguaribe.

\section{Delineamento metodológico}

O presente artigo inscreve-se na fronteira entre os campos da Saúde Coletiva e das Ciências Sociais e Humanas, por assumirem posições privilegiadas para a análise do objeto de investigação em foco. Ainda, filia-se ao enfoque qualitativo da pesquisa, tendo em vista a natureza dos fenômenos investigados.

Quanto ao local de estudo, este foi realizado na comunidade do Tomé, pertencente ao município de Quixeré, situado no baixo Jaguaribe, região do semiárido cearense. Sua escolha se deveu ao fato de apresentar, em seu território, extensa área de monocultivo de banana onde é praticado o uso intensivo de agrotóxicos por meio da pulverização costal e aérea. Esse contexto foi favorável para que a comunidade aguçasse sua percepção quanto aos riscos a que estava exposta, reconhecendo o papel dos processos produtivos como agentes transformadores de seus modos de vida, influenciando, também, no seu perfil de morbimortalidade ${ }^{8,9}$.

Para a realização dessa pesquisa, adotamos, como metodologia, a pesquisa-ação, entendida como:

[...] um tipo de pesquisa social com base empírica que é concebida e realizada em estreita associação com uma ação ou com a resolução de um problema coletivo e no qual os pesquisadores e os participantes representativos dessa situação ou do problema estão envolvidos de modo cooperativo e participativo na sua resolução. ${ }^{12}$ (p. 16)

Devido ao sincretismo teórico-conceitual que permeia o arcabouço da pesquisa-ação, alguns autores classificam-na como pesquisa participante. Porém, Thiollent ${ }^{12}$ esclarece que, apesar de identificar similitudes entre as abordagens, estas, muitas vezes, se resumem a uma dimensão semântica. Desse modo, segundo o autor:

Nossa posição é que toda Pesquisa-ação é do tipo participativa: a participação das pessoas implicadas nos problemas de investigação é absolutamente necessária. No entanto, tudo o que é chamado de Pesquisa participante não é Pesquisa-ação. Isto porque Pesquisa participante é, em alguns casos, um tipo de pesquisa baseada numa metodologia de observação participante, na qual os pesquisadores estabelecem relações comunicativas com pessoas ou grupos da situação investigada, com o intuito de serem melhor aceitos. ${ }^{12}$ (p. 17)

A argumentação acima convida-nos à reflexão de, pelo menos, duas questões fundamentais para a correta demarcação conceitual. Primeiramente, o caráter participativo dos sujeitos na pesquisa-ação apresenta-se como elemento fundante, uma característica estrutural e estruturante dessa abordagem. Em segundo lugar, o autor avança para uma qualificação acerca da participação dos sujeitos, distinguindo-a de mera observação, situação de conveniência ou simples estratégia que facilite a incursão de pesquisadores junto a sujeitos ou situações a serem investigadas.

Outra característica singular da pesquisa-ação reside na sua estrutura ontológica de base fundamentalmente social-empírica, ou seja, origina-se a partir de uma situação concreta, em que se busca sua transformação envolvendo a participação horizontal de sujeitos sociais que vivenciam cotidianamente esses problemas.

Nesse sentido, a opção pela pesquisa-ação proporciona o esteio para a superação da disjunção entre investigação e ação, ainda tão presente no campo de disputas em que se insere a produção do conhecimento $^{13}$. Em essência, tais características a distanciam de um paradigma positivista, tendo em vista que ela pressupõe a integração dialética imanente entre o sujeito e sua existência, entre fatos e valores, entre pesquisador e pesquisado e entre pesquisa e ação ${ }^{14}$. 
Para Thiollent, uma das principais etapas da pesquisa-ação consiste na formação do grupo de pesquisa que trabalhará em conjunto na identificação e resolução do problema em foco. O autor denomina esse momento de "Seminário Central", o qual, além de reunir os principais integrantes implicados no processo de investigação, tem o papel de examinar, discutir e tomar decisões acerca do percurso a ser adotado pelo grupo durante a pesquisa ${ }^{12}$.

Dessa forma, realizamos o primeiro encontro em uma Escola de Ensino Infantil e Fundamental (EEIF), localizada na comunidade do Tomé. Na ocasião, convidamos: profissionais da Atenção Primária em Saúde (enfermeiras e agentes comunitárias de saúde), professores de quatro escolas municipais, estudantes, além de moradores da comunidade. Ao todo, constituímos um grupo de vinte e quatro pessoas, com o fito de planejar e pactuar coletivamente o cronograma de trabalho estabelecido pelo grupo em três oficinas com duração de oito horas cada ${ }^{14}$.

Para cada uma das oficinas, foi elaborada uma pergunta geradora que serviu de subsídio para auxiliar o grupo a refletir sobre a problemática em questão. Dessa forma, propomos as seguintes indagações: i) Como era o passado antes da chegada das empresas do agronegócio? ii) Como avaliam o presente, a partir da chegada das empresas? iii) O que esperam do futuro?

Em diálogo com essa metodologia, adotamos o método da cartografia social, uma vez que permite:

A las comunidades conocer y construir um conocimiento integral de su território para que puedan elegir una mejor manera de vivirlo. Es una forma de investigación humanista y humanizadora.

Este tipo de mapas [...] son creados por la comunidad en un proceso de planificación participativa poniendo en común el saber colectivo y, desta forma, legitimarlo. ${ }^{15}$ (p. 8)

Desse modo, acreditamos que a cartografia social potencializa e proporciona um melhor conhecimento dos processos que determinam os problemas por meio da participação efetiva das comunidades implicadas. Nesse sentido, defendemos a ideia de que as pessoas comuns merecem conhecer mais sobre suas próprias condições de vida para defender seus interesses.

Ademais, a cartografia social, quando conjugada a metodologias que promovem uma verdadeira participação social, como a pesquisa-ação, contribui para que as comunidades construam um pensamento crítico, autônomo, libertário e emancipador, auxiliando-as a se instrumentalizarem para superar a condição de sujeitos vulnerabilizados. Dessa forma, o enfoque metodológico proposto colaborou para a estruturação de ambiências fecundas para o diálogo entre os conhecimentos científicos e populares com vistas à transformação social.

Como técnica, recorremos à utilização de entrevistas não estruturadas, sendo estas importantes ferramentas para o registro e a recuperação de memórias e identidades ameaçadas pela expansão da modernização agrícola. Dessa maneira, as mudanças impingidas pelo agronegócio são tratadas aqui como formas de aceleração da história que drasticamente alteram, por um lado, a relação do indivíduo com o tempo e que, por outro, possuem um efeito devastador e destruidor sobre o espaço, significado como um dos principais pilares da identidade: "perdido o espaço, a identidade vacila à medida que tempo/espaço compõem o quadro no interior do qual o sujeito se re-conhece"16 (p. 273).

Para a interpretação do material qualitativo, procedemos com as transcrições das gravações oriundas das entrevistas. Em seguida, submetemos os conteúdos a categorizações temáticas, estruturadas em diálogo com a literatura científica.

Concluída a fase de categorizações, procedemos à Análise de Discurso (AD), a qual procura "descrever, explicar e avaliar criticamente os processos de produção, circulação e consumo dos sentidos"17 (p. 7). Além disso, foi acordado entre os participantes da pesquisa que os discursos oriundos das entrevistas seriam tratados de maneira coletiva.

Assim, entendemos que toda produção de discursos é uma forma de ação, exigindo-nos a adoção de uma postura de detetive sociocultural. Dessa forma, acreditamos que o "analista do discurso não interpreta, ele trabalha no limite da interpretação; não se coloca fora da história, do simbólico ou da ideologia. Ele se coloca em uma posição deslocada que lhe permite contemplar o processo de produção dos sentidos em suas condições sociohistóricas"18 (p. 61). 
Destarte, a referida pesquisa foi desenvolvida em consonância com a Resolução no 196/96 do Conselho Nacional de Saúde, vigente à época, sendo também aprovada pelo Comitê de Ética em Pesquisa da Universidade Federal do Ceará.

\section{Resultados e discussão}

\section{$1^{\text {a }}$ Oficina - Territórios em transformação: o resgate do passado como instrumento de luta para o fortalecimento dos modos de vida camponeses}

Para a primeira oficina, o grupo de pesquisa promoveu uma análise coletiva do período anterior à chegada do agronegócio na região da Chapada do Apodi, buscando, com isso, resgatar as memórias populares relacionadas aos modos de vida tradicionais camponeses e o sentimento de pertença daquela comunidade aos seus territórios. Ao representar o Tomé antes da chegada dessas empresas, identificaram-se como fatores mais significativos: a vegetação nativa, a diversidade cultural, a economia de base camponesa familiar, a saúde, educação, alimentação, moradia e trabalho, conforme observamos na Figura 1.

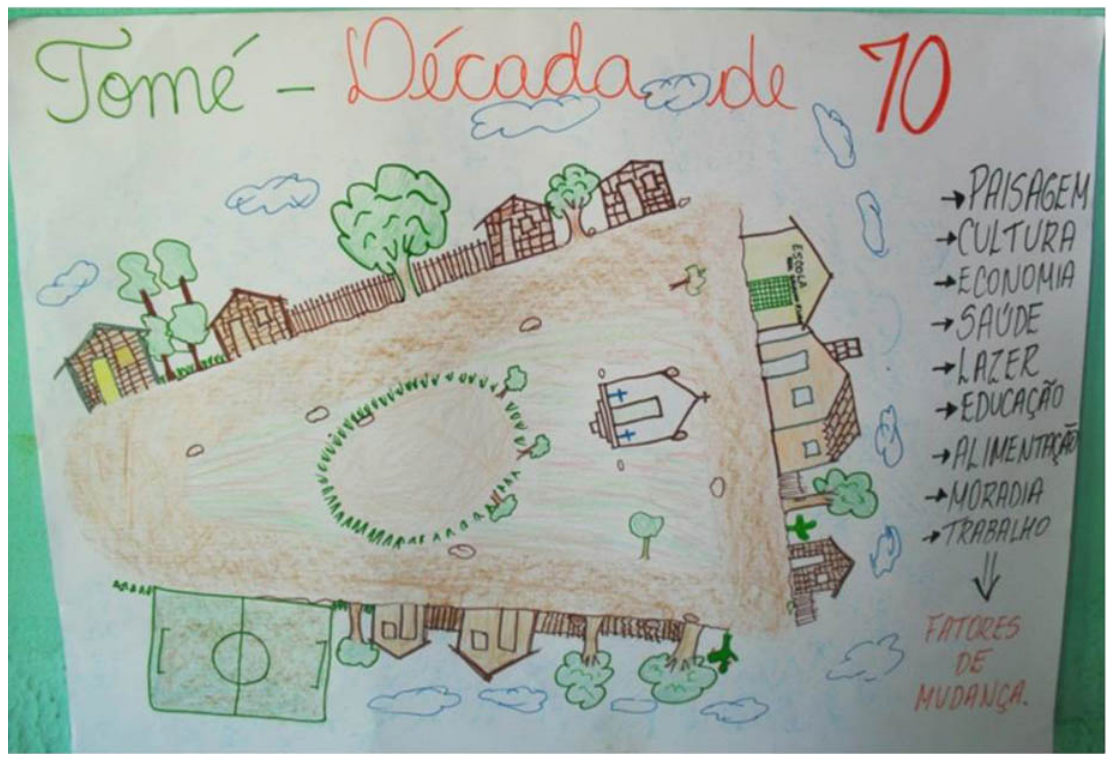

Figura 1. Representação da comunidade de Tomé na década de 1970

Fonte: Ferreira ${ }^{14}$

Nesse período, existia a presença significativa de agricultores familiares camponeses que gerenciavam o cultivo de suas terras voltado, sobretudo, para a produção de alimentos para a subsistência. A agricultura era predominantemente de sequeiro: plantavam milho, feijão, mandioca, além de frutas, como goiaba e mamão. O cultivo era feito utilizando-se técnicas simples, sem a intervenção de maquinários agrícolas, sem a necessidade de melhoramento genético das sementes, muito menos, de implementos, como herbicidas e fungicidas ${ }^{19}$. 
Outro ponto importante dessa oficina se refere ao resgate das memórias populares camponesas relacionadas ao período anterior à chegada dos empreendimentos de fruticultura irrigada. Esta oficina cumpriu um importante papel social na medida em que contribuiu para reafirmar a existência e a diversidade sociocultural da comunidade do Tomé. Dessa forma, conseguem contrapor os discursos difundidos pelos empresários do setor quando afirmavam que "não existia vida na Chapada do Apodi antes do agronegócio" 20 (p. 48). Em verdade, tais condutas fazem parte da conformação de um mito ideológico, cuja finalidade reside em promover processos de invisibilização e de dominação para com as populações tradicionais e seus territórios.

Esse contexto se insere no que Boaventura de Sousa Santos ${ }^{21}$ denomina por "sociologia das ausências". De acordo com o autor, "há produção de não existência sempre que uma entidade é desqualificada e tornada invisível, inteligível ou descartável"21 (p. 102). Esse processo se espraia tanto na dimensão epistemológica quanto na jurídica: epistemológica porque tornam invisibilizadas e até marginalizadas as culturas e os conhecimentos tradicionais, relegados ao estatuto de magia, entendimentos subjetivos ou, na melhor das hipóteses, matéria-prima de investigações científicas; jurídica porque se consubstancia a partir de concessões feitas pelo próprio Estado, tendo, como principal expressão local, a construção dos Perímetros Irrigados durante as décadas de 1960 e 1970.

Como corolário, cerca de trezentas e vinte famílias foram desapropriadas de suas terras para dar lugar aos canais de irrigação, promovendo, com isso, profundas modificações socioespaciais e simbólicas, reconfigurando a paisagem, os modos de vida das famílias e dando lugar a um novo território, "projetado para atender aos interesses econômicos e políticos do Estado"22 (p. 89). Nesse contexto, registra-se a chegada do agronegócio no baixo Jaguaribe, não para tornar produtivo um espaço "improdutivo", muito menos povoar uma região inabitada, mas para extrair desses territórios os seus recursos, sejam naturais, humanos, políticos e econômicos ${ }^{20}$.

\section{$2^{a}$ Oficina - A reconfiguração socioespacial promovida pelo agronegócio}

Na segunda oficina, o grupo de pesquisa cartografou a comunidade na década de 2010, demonstrando, de forma clara, as profundas transformações nos territórios oriundas da chegada do agronegócio. Identificamos, na Figura 2, uma reconfiguração socioespacial que se inicia a partir da construção do Perímetro Irrigado Jaguaribe-Apodi, servindo de infraestrutura física para a instalação das empresas de fruticultura irrigada.

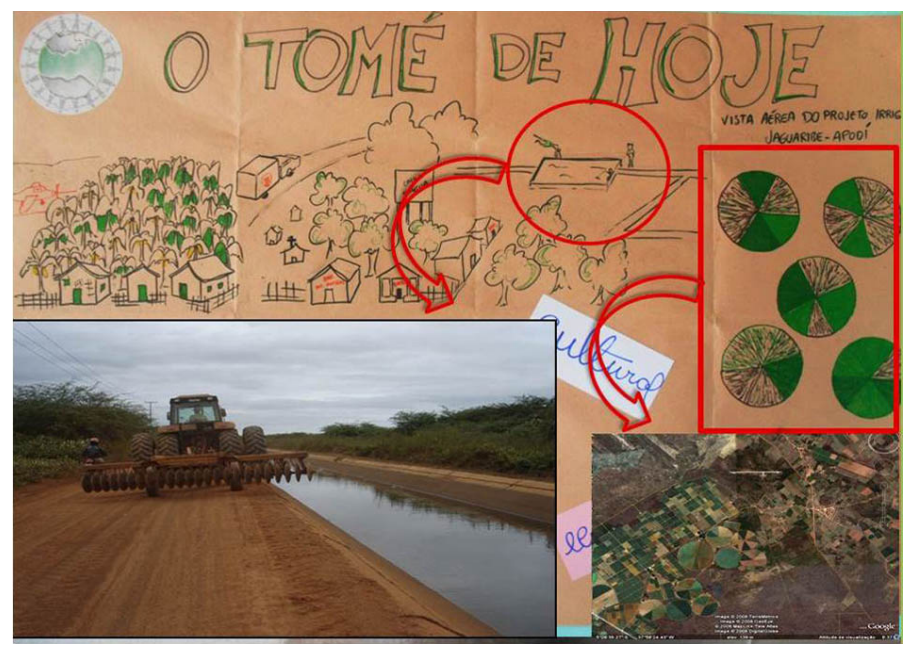

Figura 2. Representação da comunidade do Tomé no presente.

Fonte: Ferreira ${ }^{14}$ 
Desse modo, a agricultura de sequeiro, pouco a pouco, foi substituída pelos monocultivos, cuja produção é parcial ou totalmente vendida para as grandes empresas, estabelecendo, assim, um vínculo de dependência entre o pequeno agricultor camponês e os empresários do agronegócio. De acordo com o discurso abaixo:
"As formas que as comunidades tinham de produzir e de plantar foram totalmente mudadas por conta do Perímetro, por conta da realidade que eles trouxeram e enganaram as pessoas dizendo que era uma coisa muito boa, que o certo [...] era plantar do jeito que eles plantavam. Foi uma história que eles inventaram e que muita gente acreditou e que até hoje estão pagando o preço".

Além da perda da fauna e flora nativas, registrou-se, também, um expressivo número de expropriações entre os agricultores camponeses:

Do total de 116 pequenos agricultores (irrigantes) da área-piloto (área com lotes de quatro e 16 hectares), permaneceram no projeto, em 2009, apenas dois, representando uma expropriação de $98 \%$. Restavam assim, apenas $2 \%$ no projeto, ou seja, dos 334 ocupantes oficiais, apenas 0,6\% desse número faziam parte dos selecionados em 1992. Após a expropriação, dois fenômenos, decorrentes desse processo, podem ser observados: o primeiro é a redução das áreas daqueles agricultores resistentes [...]; o segundo é a ampliação exponencial das áreas de médios/grandes produtores e das empresas, levando à concentração de terra, que se projeta por meio da compra da posse ou da invasão. ${ }^{22}$ (p. 101-3)

Além disso, processos produtivos como o agronegócio contribuem para a introdução de contextos de risco que influenciam sobremaneira na saúde dos trabalhadores, bem como das populações circunvizinhas, incidindo, direta e indiretamente, sobre seu perfil de morbimortalidade.

Acerca disso, cita-se um estudo epidemiológico, conduzido nos municípios de Limoeiro do Norte, Russas e Quixeré, que envolveu 545 trabalhadores rurais utilizando exames clínicos e provas laboratoriais. Destes, 46,6\% relacionaram algum problema de saúde aos agrotóxicos, e 43,3\% referiram-se a sinais e sintomas compatíveis com intoxicações agudas em sua história pregressa. Chamou a atenção o quantitativo de $30,7 \%$ de trabalhadores que, no momento do exame, apresentaram quadros semelhantes a intoxicações agudas por agrotóxicos ${ }^{23}$.

Em relação à função hepática, dos nove indicadores laboratoriais utilizados para avaliação, todos apresentaram algum tipo de variação, sugerindo hipertrofia e necrose dos hepatócitos, colestase e danos das vias biliares. A transaminase oxalacética elevou-se em $6,2 \%$, a transaminase pirúvica, em $14 \%$ dos casos, e a fosfatase alcalina, em $6,2 \%$. Ressalta-se que esses três indicadores são utilizados pela Organização Pan-Americana de Saúde (OPAS) para correlacionar lesões hepáticas crônicas à exposição por agrotóxicos ${ }^{23}$.

Outro estudo, realizado em Limoeiro do Norte com trabalhadores rurais produtores de banana, concluiu que a exposição crônica aos agrotóxicos levou à ocorrência de alterações cromossômicas em células da medula óssea. De 35 amostras viáveis, 11 apresentaram importantes alterações cromossômicas, sendo elas: deleções dos cromossomos 5, 7 e 11; monossomia do TP53 e a amplificação do TP53. As anormalidades encontradas são semelhantes às alterações descritas em doenças clonais da medula óssea, como síndromes mielodisplásica e leucemias mielóide agudas ${ }^{24}$.

O incremento de neoplasias e outros agravos relacionados aos agrotóxicos na região da Chapada do Apodi também está presente nos discursos do grupo de pesquisa, conforme identificamos abaixo:

"Quantas e quantas pessoas aqui já morreram de câncer? Quantas e quantas têm câncer ou estão em situação complicada? Se a gente for fazer hoje uma análise da nossa comunidade, $70 \%$ das famílias toma remédio para estômago. Na nossa comunidade já teve gente que morreu com problema de fígado, de úlcera, já tem gente operada que foi preciso tirar parte do estômago". 
Todos esses dados dialogam com o contexto vivenciado pelas comunidades do baixo Jaguaribe. Um estudo transversal, realizado a partir de registros de dados secundários, calculou a Razão Proporcional de Incidência de Câncer (PCIR) nas principais localizações anatômicas de câncer no estado do Ceará. Os resultados demonstraram um maior risco de câncer em agricultores da região quando comparados a não-agricultores em 15, das 23 localizações estudadas, sendo as maiores diferenças para câncer no pênis $(6,44)$, leucemias $(6,35)$ e testículos $(5,77)^{25}$.

Do ponto de vista da exposição ambiental, destacamos, na Figura 2 (círculo), o canal que é responsável pela captação das águas do rio Jaguaribe até o topo da Chapada. Essas percorrem uma distância de 14 quilômetros a céu aberto e, apesar de serem apropriadas apenas para a irrigação, diversas famílias as utilizam para consumo próprio por falta de opção. Somam-se, ainda, registros imagéticos e relatos de que tratores e maquinários agrícolas utilizados na aplicação de agrotóxicos nas plantações lavam seus equipamentos nas águas desse canal, representando um grave risco de contaminação química, além da possibilidade de transmissão de doenças por veiculação hídrica ${ }^{14}$.

Ademais, ressaltamos, na Figura 2, a representação de um avião próximo às plantações de banana, retratando a pulverização aérea praticada à época na comunidade. Quanto à classificação toxicológica dos agrotóxicos utilizados, são extremamente ou muito tóxicos. Importante salientarmos que, de acordo com as informações obtidas nas Fichas de Segurança Química dos diferentes fabricantes desses fungicidas, podem ser esperados sinais e sintomas clínicos em seres humanos acometendo desde a pele e as mucosas até o Sistema Nervoso Central ${ }^{11,26}$.

\section{$3^{\mathrm{a}}$ Oficina - Em meio à expansão do agronegócio, um horizonte de esperanças transformadoras}

Na última oficina, tratamos de problematizar o futuro da comunidade do Tomé, caso perdurasse a expansão do agronegócio. Para tanto, o grupo realizou um trabalho dando destaque à contaminação por agrotóxicos, sobretudo dos trabalhadores e trabalhadoras dessas empresas.

Chamou a atenção a forma como a comunidade retratou os problemas oriundos da contaminação ambiental e exposição a contaminantes químicos. O trabalho, que deveria ser fonte de realização e prosperidade, fora associado a uma caveira, demonstrando a correlação perigosa do agricultor com os agrotóxicos, conforme observamos na Figura 3.

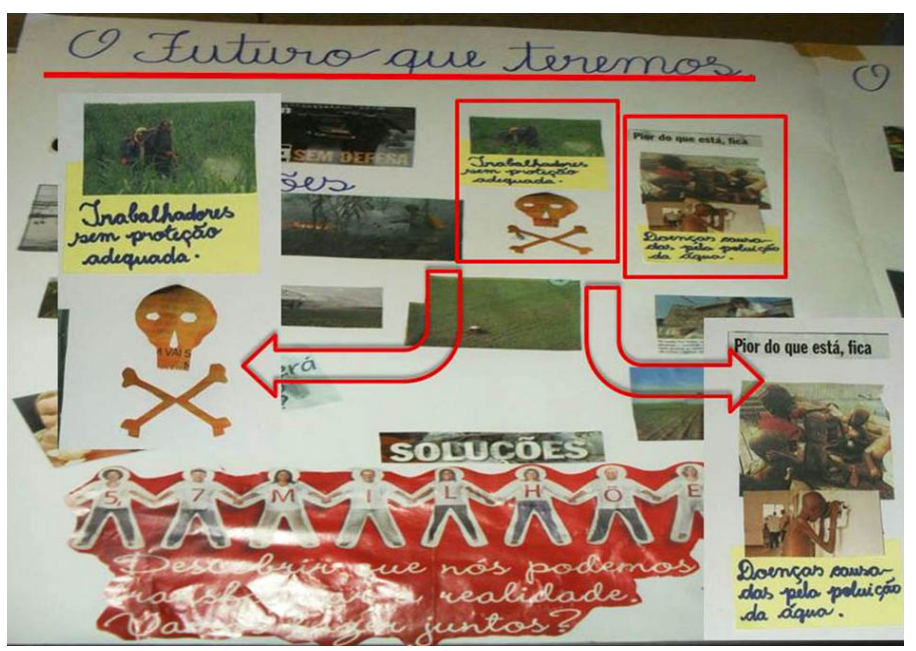

Figura 3. Representação sobre o futuro da comunidade do Tomé 
A insalubridade presente no cotidiano dos agricultores e agricultoras que trabalham no agronegócio também é reafirmada no discurso do grupo de pesquisa, conforme demonstramos abaixo:

"A maioria das mulheres adoece de problemas no útero. É o que dá mais. E por que dá mais doenças de útero? Porque as mulheres passam o dia todo naquelas plantações cuidando das frutas e os homens atrás com as bombas nas costas expurgando [veneno]".

Nesse quesito, estudo realizado sobre a percepção dos trabalhadores do agronegócio sobre seu trabalho evidenciou sua exposição direta aos pesticidas, ampliando os riscos de intoxicação aguda por inalação, além da absorção por via dérmica e digestiva ${ }^{27}$.

Em relação à contaminação ambiental, observamos o destaque concedido pelo grupo, sobretudo envolvendo as águas para consumo humano. Mesmo inserindo imagens de crianças adoecidas e relacionando essas patologias à poluição das águas, ainda acrescentou-se a frase "pior que está fica", retratando seu receio e insegurança quanto a essa questão para o futuro.

Tal preocupação ganha relevo, tendo em vista que, em estudo realizado por Rigotto ${ }^{8}$, foram coletadas 24 amostras de água provenientes de diversos pontos, como canais que abastecem as comunidades, caixas d'água e poços profundos. Em todas as amostras, foram detectados princípios ativos de agrotóxicos. Somente em um poço profundo localizado no distrito de Tomé, foram identificados 12 princípios ativos. Dentre eles, a maioria era de classificação toxicológica I e II, extremamente e altamente tóxicos, respectivamente.

A preocupação das comunidades ainda é potencializada, pois o estado do Ceará não possui dados referentes ao monitoramento de agrotóxicos na água para consumo humano no Sistema de Informação de Vigilância da Qualidade da Água para Consumo Humano ${ }^{28}$. Isso representa uma verdadeira invisibilidade para o Sistema Único de Saúde, que fica impossibilitado de reunir informações para o desenvolvimento de ações de vigilância e controle da qualidade da água para consumo humano. Além disso, a ausência dessas informações representa uma negação dos direitos das comunidades de conhecerem a real qualidade da água que consomem.

Apesar de todas as denúncias e incertezas representadas na Figura 3, o grupo também apontou para soluções viabilizadas de forma coletiva, retratadas a partir de uma colagem de várias pessoas de mãos dadas, com a frase "descobrir que nós podemos mudar a realidade. Vamos fazer juntos?". Talvez essa imagem represente a força existente nas organizações populares, aliada ao seu desejo de transformar suas comunidades em lugares melhores para se viver.

\section{Considerações finais}

A crescente expansão do agronegócio no Brasil pode ser mensurada pela magnitude do seu faturamento, sobretudo nos últimos dez anos. A cada ano, esse "modelo" de produção químicodependente expande suas fronteiras para diversas regiões do país.

Esse contexto favorece o surgimento de novos e mais complexos conflitos territoriais entre as comunidades tradicionais, sobretudo as camponesas. Como corolário, acentua-se o desequilíbrio ambiental materializado em diferentes dimensões, tais como: a perda da fauna e flora nativa em detrimento da introdução dos monocultivos; a contaminação dos solos e dos lençóis freáticos, contribuindo para acentuarem a insegurança hídrica, sobretudo no semiárido. Merecem destaque, ainda, as condições de trabalho, muitas vezes insalubres e adoecedoras, presentes no cotidiano dos agricultores que trabalham no agronegócio, contribuindo para ampliar o quantitativo de intoxicações agudas e acidentes de trabalho.

Ressaltamos, ainda, a influência desses processos produtivos sobre o perfil de morbimortalidade das comunidades, sobretudo das que vivem no entorno desses empreendimentos, promovendo uma maior incidência no surgimento de neoplasias que podem estar relacionadas com os agrotóxicos utilizados nos cultivos. 
Nesse contexto, cresce cada vez mais a necessidade de novas parcerias entre Universidades, movimentos sociais e comunidades atingidas, de forma a contribuir com a organização popular, dando visibilidade aos conflitos socioambientais e qualificando suas reivindicações por melhores condições de saúde, trabalho e ambiente.

Por meio das oficinas, pudemos experienciar, na prática, o desenvolvimento da consciência coletiva dos sujeitos nos planos cultural, ideológico e político. Ao problematizar sua própria realidade, dialogando com diferentes temporalidades, o grupo obteve maior clareza sobre as transformações que incidem em seus territórios desde a chegada do agronegócio.

Essas características se aproximam dos pressupostos epistemológicos da pesquisa-ação, em que a práxis é concebida como mediação básica da construção do conhecimento. Nesse sentido, o saber produzido é necessariamente transformador de sujeitos e circunstâncias.

\section{Colaboradores}

Os autores participaram, igualmente, de todas as etapas de elaboração do artigo.

\section{Referências}

1. Sindicato Nacional das Indústrias de Defensivos Agrícolas (BR). Dados de produção e consumo de agrotóxicos [Internet]; 2010 [acesso 2010 Jan 10]; Disponível em: http://www.sindag.com.br

2. Pelaez V. Monitoramento do mercado de agrotóxicos [Internet]. Brasília (DF): Agência Nacional de Vigilância Sanitária; 2012 [acesso 2014 Jul 16]. Disponível em: http:// portal.anvisa.gov.br/wps/wcm/connect/c4bdf280474591ae99b1dd3fbc4c6735/estudo_ monitoramento.pdf?MOD=AJPERES

3. Sindicato Nacional das Indústrias de Defensivos Agrícolas. (BR) Dados de produção e consumo de agrotóxicos [Internet]; 2012 [acesso 2012 Maio 7]. Disponível em: http://www.sindag.com.br

4. Sindicato Nacional das Indústrias de Produtos para a Defesa Vegetal (BR). Dados de investimento em tecnologia [Internet]; 2013 [acesso 2013 Fev 5]. Disponível em: http//:www.sindiveg.org.br

5. Ministério da Saúde (BR). Sistema de Informação de Agravos de Notificação. Banco de dados eletrônicos [Internet]. Brasília (DF): SINAN; 2014 [acesso 2014 set 21]. Disponível em: http://drt2004.saude.gov.br/sinanweb 
6. Ministério da Saúde (BR). DATASUS. Sistema de Informação de Agravos de Notificação [Internet]. Brasília (DF): SINAN; 2012 [acesso 2014 Abr 23]. Disponível em: http://tabnet. datasus.gov.br/sinanweb

7. Ministério da Saúde (BR). DATASUS. Sistema de Informação de Agravos de Notificação [Internet]. Brasília (DF): SINAN; 2013 [acesso 2014 Abr 30]. Disponível em: http://tabnet. datasus.gov.br/sinanweb

8. Rigotto RM. Agrotóxicos, trabalho e saúde: vulnerabilidade e resistência no contexto da modernização agrícola no baixo Jaguaribe/CE. Fortaleza: Edições UFC; 2011.

9. Rigotto RM, Silva AMC, Ferreira MJM, Rosa IF, Aguiar ACP. Tendências de agravos crônicos à saúde associados a agrotóxicos em região de fruticultura no Ceará, Brasil. Rev Bras Epidemiol. 2013; 16(3):763-73.

10. Companhia de Gestão dos Recursos Hídricos. Plano de gestão participativa dos aquíferos da bacia Potiguar, estado do Ceará. Fortaleza: COGERH; 2009.

11. Ferreira MJM. Inflexões do Estado frente ao agronegócio e suas implicações para a Saúde e o Ambiente [Internet]. In: Anais do $2^{\circ}$ Simpósio Brasileiro de Saúde Coletiva; 2014; Belo Horizonte; Brasil. Belo Horizonte: Associação Brasileira de Saúde Coletiva; 2014. p. 2-9 [acesso 2014 Nov 20]. Disponível em: http://www.sibsa.com.br/site/ anaisarquivoresumo.

12. Thiollent M. Metodologia da pesquisa-ação. 17a ed. São Paulo: Cortez; 2009.

13. Bourdieu P. O poder simbólico. 14a ed. Rio de Janeiro: Bertrand Brasil; 2010.

14. Ferreira MJM. Contribuições epistemológicas/metodológicas para o fortalecimento de uma (Cons)ciência emancipadora [dissertação]. Fortaleza (CE): Universidade Federal do Ceará; 2012.

15. Soliz F, Maldonado A. Guia de metodologias comunitárias participativas. Quito: Clínica Ambiental; 2012.

16. D'alessio MM. Intervenções da memória na historiografia: identidades, subjetividades, fragmentos, poderes. São Paulo: Projeto História; 1998.

17. Pinto MJ. Comunicação e discurso: introdução a análise de discurso. São Paulo: Hacker Editores; 1999.

18. Orlandi EP. Análise de discurso: princípios e procedimentos. Campinas: Pontes; 2000.

19. Sampaio JLF, Lima AEF, Freitas BMC. As bases geo-históricas do Baixo Jaguaribe. In: Rigotto RM, organizador. Agrotóxicos, trabalho e saúde: vulnerabilidade e resistência no contexto da modernização agrícola no Baixo Jaguaribe/CE. Fortaleza: Edições UFC; 2011. p. 111-43.

20. Núcleo Tramas. Almanaque do Baixo Jaguaribe ou tramas para a afirmação do trabalho, meio ambiente e saúde para a sustentabilidade. Fortaleza: Expressão Gráfica; 2012.

21. Santos BS. A gramática do tempo: para uma nova cultura política. 2a ed. São Paulo: Cortez; 2008.

22. Freitas BMC. Marcas da modernização da agricultura do Perímetro Irrigado JaguaribeApodi: uma face da atual reestruturação socioespacial do Ceará [dissertação]. Fortaleza (CE): Universidade Estadual do Ceará; 2010.

23. Rosa IF, Pessoa VM, Rigotto RM. Introdução: agrotóxicos, saúde humana e os caminhos do estudo epidemiológico. In: Rigotto RM, organizador. Agrotóxicos, trabalho e saúde: vulnerabilidade e resistência no contexto da modernização agrícola no Baixo Jaguaribe/CE. Fortaleza: Edições UFC; 2011. p. 217-56. 
24. Ferreira Filho LIP. Estudo das alterações citogenômicas na medula óssea de trabalhadores rurais expostos à agrotóxicos [dissertação]. Fortaleza (CE): Universidade Federal do Ceará; 2013.

25. Ellery AEL, Arregi MMU, Rigotto, RM. Incidência de câncer em agricultores em hospital de câncer no Ceará. In: Anais do 18th IEA World Congresso of Epidemiology, 70 Congresso Brasileiro de Epidemiologia; 2008; São Paulo; Brasil. São Paulo: Abrasco; 2008. Disponível em: http://www.epi2008.com.br/ingles/index.php

26. Marinho AMCP. Contextos e contornos da modernização agrícola em municípios do baixo Jaguaribe-CE: o espelho do (des)envolvimento e seus reflexos na saúde, trabalho e ambiente [tese]. São Paulo (SP): Faculdade de Saúde Pública, Universidade de São Paulo; 2010.

27. Ferreira MJM, Teixeira AAT, Marinho AMCP. Centralidade do trabalho e sua caracterização nos diferentes contextos da produção agrícola no baixo Jaguaribe. In: Rigotto RM, organizador. Agrotóxicos, trabalho e saúde: vulnerabilidade e resistência no contexto da modernização agrícola no Baixo Jaguaribe/CE. Fortaleza: Edições UFC; 2011. p. 296-318.

28. Ministério da Saúde. Secretaria de Vigilância em Saúde. Monitoramento de Agrotóxicos na Água para Consumo Humano no Brasil, 2011/2012. Bol Epidemiol. 2013; 44(17): 10 .

Ferreira MJM, Viana Júnior MM. La expansión del agronegocio en la región semiárida de Ceará y sus implicaciones para la salud, el trabajo y el medio ambiente. Interface (Botucatu). 2016; 20(58):649-60.

Desde 2008, Brasil es el líder mundial en consumo de plaguicidas. Sin embargo, desde punto de vista sanitario, aumentan las tasas de envenenamiento por pesticidas. Sólo en el año 2012, las mismas superaron las 9000 notificaciones. Este artículo tiene como objetivo el análisis de las transformaciones ocurridas en los modos de vida - junto con sus consecuencias para la salud, trabajo y ambiente - derivados de la introducción/ expansión del agronegocio en Ceará. En la presente investigación, adoptamos la metodología de la investigación-acción. Como método, utilizamos la Cartografía Social y la entrevista no estructurada como técnica. Así mismo, el análisis del material cualitativo se produjo a través del Análisis del Discurso. Por medio de talleres, tuvimos la posibilidad de experimentar en la práctica el desarrollo de la conciencia colectiva de los sujetos participantes en la investigación. Al problematizar su propia realidad, obtuvieron una perspectiva de mayor profundidad acerca de los cambios que se recaen sobre sus territorios como consecuencia de la agroindustria.

Palabras clave: Vulnerabilidad social. Exposición a riesgos ambientales. Plaguicidas. Asentamientos rurales. Participación comunitaria. 